\title{
EFFECTS OF TAMPON MATERIALS ON THE IN-VITRO PHYSIOLOGY OF A TOXIC SHOCK SYNDROME STRAIN OF STAPHYLOCOCCUS AUREUS
}

\author{
Eileen Ingham, E. Anne Eady*, K. T. Holland* and G. Gowland
}

Departments of Immunology and *Microbiology, University of Leeds, Leeds LS2 9JT

\begin{abstract}
SUMmaRY. Seven materials used in the manufacture of tampons-four rayon, one modified rayon, one cotton and one carboxy-methyl cellulose (a modified cotton)-were compared for their effects in vitro on the physiology of a strain of Staphylococcus aureus isolated from a patient with Toxic Shock Syndrome. Experiments were performed in broth culture and, with the exception of two rayon samples, all of the materials tested reduced growth rate and cell yield compared with control values.

Exocellular acid phosphatase, lipase, proteinase, hyaluronate lyase and haemolysin in culture filtrates were measured and the lethality of filtrates was determined in mice. The tampon materials had different effects on the levels of exocellular products. Cotton and carboxy-methyl cellulose cotton materials reduced the levels of all of the activities tested. The activities of the other enzymes were reduced or increased, depending on which material was present. All materials reduced both haemolytic activity and lethality of the culture filtrates.

The in-vitro data suggest an extremely complex interaction between tampon materials and $S$. aureus.
\end{abstract}

\section{INTRODUCTION}

There is considerable evidence implicating Staphylococcus aureus in the aetiology of Toxic Shock Syndrome (TSS) (Barbour, 1981; Bergdoll et al., 1981; Schlievert et al., 1981 and 1982; Vergeront et al., 1982; Schlievert, 1983). The evidence indicates that TSS in menstruating women depends upon several factors, viz., the host, the presence of a strain of $S$. aureus with a phenotype for TSS-toxin-I production and the vaginal environment, which includes the tampon in tampon-associated TSS cases. It is, therefore, surprising that very little information is available about the effects of tampon materials on the growth and exocellular product formation of $S$. aureus. Broome $e$ al. (1982) failed to demonstrate a significant effect of tampon materials on the growth of $S$. aureus in vitro.

Received 10 Apr. 1984; revised version accepted 3 Dec. 1984.

Address for correspondence: Dr. Eileen Ingham, University Department of Immunology, The General Infirmary, Great George Street, Leeds LS1 3EX. 
In this study we investigated the effects of exposure to various tampon materials on the physiology of a single TSS strain of $S$. aureus in vitro. Our aim was to determine whether such materials altered the growth rate, cell yield or exocellular enzyme production either directly, by inhibition or stimulation, or indirectly by absorption phenomena. A preliminary letter-report about this work (Eady et al., 1983) showed that different tampon materials had different effects on the physiology of this $S$. aureus strain in vitro. Here the study is enlarged upon and its results are presented and discussed in greater detail.

\section{MATERIALS AND METHODS}

Bacterial strain. S. aureus (FRI 1187 TSS-toxin-I positive), isolated from a case of TSS, was kindly supplied by Professor M. S. Bergdoll, Department of Food Microbiology and Toxicology, University of Wisconsin-Madison; it was used throughout this study.

Growth medium. Strain FRI 1187 was grown in Brain Heart Infusion Broth (BHI; Difco), supplemented with sterile salts $(\mathrm{mg} / \mathrm{L})$ as follows: $\mathrm{Mg}_{2} \mathrm{SO}_{4} \cdot 7 \mathrm{H}_{2} \mathrm{O}(200) ; \mathrm{C}_{6} \mathrm{H}_{5} \mathrm{O}_{7} \mathrm{Fe} \cdot 5 \mathrm{H}_{2} \mathrm{O}(10)$; $\mathrm{MnSO}_{4} \cdot 4 \mathrm{H}_{2} \mathrm{O}(10) ; \mathrm{NaCl}(10) ; \mathrm{CaCl}_{2}(10) ; \mathrm{ZnCl}_{2}(5) ; \mathrm{CoNO}_{3}(5) ; \mathrm{CuSO}_{4}(0 \cdot 5)$.

Tampon materials. Seven materials used in the manufacture of European and American tampons were studied. These were: unmodified rayon (four samples R1-R4); unmodified cotton (C); acrylate/methyl-acrylate modified rayon and carboxy-methyl cellulose modified cotton linters (MAR and CMC respectively; known as superabsorbents).

Inocula. Starting inocula of strain 1187 were each grown for $18 \mathrm{~h}$ in $50 \mathrm{ml}$ of BHI plus salts in a $250-\mathrm{ml}$ flask at $37^{\circ} \mathrm{C}$ on an orbital shaker at $160 \mathrm{rpm}$. The cells from a culture were centrifuged and washed twice in medium and then resuspended in $10 \mathrm{ml}$ of warm medium.

Inoculation, incubation and sampling conditions. Five control cultures were grown, each on a separate occasion. These cultures consisted of medium alone ( $500 \mathrm{ml}$ in 2-L baffle flasks) and 2 $\mathrm{ml}$ of the washed cell inoculum. Cultures were incubated at $37^{\circ} \mathrm{C}$ on an orbital shaker at $160 \mathrm{rpm}$ for $24 \mathrm{~h}$. Samples $(10-30 \mathrm{ml})$ were removed aseptically at intervals and optical density measurements were made on a Pye Unicam SP600 spectrophotometer at $600 \mathrm{~nm}$ to determine the initial growth rate. Dilutions, when necessary, were made in BHI plus salts. Supernates were obtained by centrifugation $(3000 \mathrm{~g} ; 10 \mathrm{~min})$ and their $p \mathrm{H}$ values recorded. Yield of growth $(\mathrm{mg} / \mathrm{ml})$ was determined as described by Ingham et al. (1983). The $p \mathrm{H}$ of the supernates was adjusted to 7.4 before sterilisation by filtration through cellulose acetate membrane filters (Mini-sarts, pore size $0.45 \mu \mathrm{m}$ : Sartorious Ltd). Divided small volumes of the filtrates were stored at $-70^{\circ} \mathrm{C}$ until assayed for exocellular enzyme activities.

Separate media containing each of the seven test materials were prepared as follows: $25 \mathrm{~g}$ of each material was added aseptically to growth medium ( $500 \mathrm{ml}$ in a 2-L baffle flask) after autoclaving. The materials themselves were not sterilised before use. The base medium and the seven media with materials were then each inoculated with $2 \mathrm{ml}$ of the washed cell inoculum. The eight cultures were incubated and all sampled simultaneously as described above for control-culture tests.

Assays for exocellular enzymes and haemolytic activity were performed in duplicate, with suitable positive and negative controls included. Lethality tests were single determinations.

Acid phosphatase was determined by the method of Ingham et al. (1980), modified for $S$. aureus. The substrate used was 4-nitrophenyl disodium orthophosphate $(2 \cdot 5 \% \mathrm{w} / \mathrm{v}$ in $0 \cdot 1 \mathrm{M}$ sodium acetate buffer $p \mathrm{H} 5.2$ plus $0.017 \mathrm{M} \mathrm{Mg}_{2} \mathrm{SO}_{4}$ ) and incubation was for $15 \mathrm{~min}$ at $37^{\circ} \mathrm{C}$. One unit of acid phosphatase is the amount required to release $1 \mu \mathrm{mol}$ of 4-nitrophenol/min.

Lipase was assayed as described by Ingham et al. (1981), except that triolein $20 \% \mathrm{w} / \mathrm{v}$ in 0.05 $\mathrm{M}$ Tris $\left(p \mathrm{H} \mathrm{7.0)}\right.$ was used as the substrate and incubation was for $15 \mathrm{~min}$ at $37^{\circ} \mathrm{C}$. One unit of lipase released $1 \mu \mathrm{mol}$ of oleic acid/min.

Proteinase was estimated by the method of Millet (1970) with azocasein (Sigma) as substrate. The reaction mixture contained $1 \% \mathrm{w} / \mathrm{v}$ azocasein in $0.2 \mathrm{M}$-Mes $(p \mathrm{H} 7 \cdot 2)$ plus $10^{-3} \mathrm{M} \mathrm{CaCl}_{2}$ and 1 $\mathrm{ml}$ of culture supernate. Trichloroacetic acid $(2 \mathrm{ml} ; 10 \% \mathrm{w} / \mathrm{v})$ was added to control tubes at time zero and to assay tubes after $3 \mathrm{~h}$ at $37^{\circ} \mathrm{C}$. The absorbance at $440 \mathrm{~nm}$ was recorded after filtration 
to remove the precipitated azocasein. One unit of proteinase is defined as the amount required to increase the $\mathrm{OD}_{440}$ by $1 \times 10^{-3}$ units/h.

Hyaluronate lyase was estimated by the method of Ingham et al. (1979), with sodium hyaluronic acid (Sigma) $0.6 \% \mathrm{w} / \mathrm{v}$ in $0.05 \mathrm{M}$ sodium acetate buffer $(p \mathrm{H} 5 \cdot 2)$ plus $0.1 \mathrm{M} \mathrm{NaCl}$ as the substrate. One unit of hyaluronate lyase releases $1 \mu \mathrm{mol}$ of $\mathrm{N}$-acetyl-d-glucosamine $/ \mathrm{min}$.

Haemolysin. Haemolytic activity was determined against rabbit red-blood cells $5 \% \mathrm{v} / \mathrm{v}$ in RPMI tissue culture medium (Gibco). The highest dilution (two-fold) which reduced the turbidity of the RBC suspension by $50 \%$ was regarded as the end point and considered to contain one unit of haemolysin/ml.

Lethality (LD50 determinations). Dilutions of $S$. aureus sterile culture filtrate in BHI plus salts $(0.5 \mathrm{ml})$ and BHI plus salts alone $(0.5 \mathrm{ml}$; control) were injected into the tail vein of Balb C mice $(c .20 \mathrm{~g})$. Lethality was recorded as death within a 40 -h period after injection. Initially, two mice for each doubling dilution were used to titrate lethality. Lethality is expressed as units of dilution per ml. The culture filtrates showing lethality at a dilution greater than 1 in 2 (4 lethal units) were re-tested to determine the LD50. Five mice at each of five dilutions between the previously determined lethal and non-lethal two-fold dilutions were tested (e.g., at dilutions of 8 , $10,12,14$, and 16 for the control culture at $10 \mathrm{~h}$ ). LD50's were calculated as described by Reed and Muench (1938) and are expressed as the dilution required for $0.5 \mathrm{ml}$ to $\mathrm{kill} 50 \%$ of the 25 mice tested.

Treatment of preformed exocellular proteins with tampon materials A 24-h control $S$. aureus culture filtrate $(60 \mathrm{ml})$ was divided into three aliquots. One aliquot (the control) received no treatment. To each of the remaining aliquots, $1 \mathrm{~g}$ of rayon (R4) or carboxy-methyl cellulose modified cotton linters (CMC) was added and the mixtures were incubated at $37^{\circ} \mathrm{C}$ on an orbital shaker at $160 \mathrm{rpm}$ for $30 \mathrm{~min}$. These were then placed in plastic syringes $(20 \mathrm{ml}$ capacity; Sterilin Ltd) adapted into "columns" by packing the material with fluid into the syringe cylinder. Four $5-\mathrm{ml}$ fractions were collected at a rate of $20 \mathrm{ml} / \mathrm{h}$ under positive pressure. The columns were then washed with $20 \mathrm{ml}$ of PBS, to remove loosely bound proteins, and then again with $20 \mathrm{ml}$ of PBSplus $0.4 \mathrm{M} \mathrm{NaCl}$ to remove adsorbed proteins. As before, four $5-\mathrm{ml}$ fractions were collected from each washing, at the same flow rate. Each fraction was assayed for exocellular proteins and ions. The use of positive pressure in these procedures ensured that there was negligible retention of fluid by the materials in the columns.

Ion determinations. $\mathrm{Fe}^{2+} \mathrm{Na}^{+}, \mathrm{K}^{+}, \mathrm{Cl}^{-}, \mathrm{Ca}^{+}$and $\mathrm{PO}_{4}{ }^{2-}$ levels were determined colorimetrically by a Technicon AA 1 analyser, in the Leeds University Department of Chemical Pathology.

Glucose determinations. Glucose was assayed by Sigma Glucose assay kit SIOA.

\section{RESULTS}

One of the five repeat control growth curves of $S$. aureus FRI 1187 in BHI plus salts is shown in fig. 1 . After a short lag $(1.5 \mathrm{~h})$, growth continued for $8 \mathrm{~h}$, when the culture entered the stationary phase. Glucose was utilised during the first $6 \mathrm{~h}$ and the $p \mathrm{H}$ dropped from $7 \cdot 4$ to 6.1 during the first $3 \mathrm{~h}$, then rose steadily to reach $p \mathrm{H} 8.0$ by $24 \mathrm{~h}$. Exocellular enzyme production began within the first $2 \mathrm{~h}$ of growth (fig. 1). The culture filtrates obtained after $4 \mathrm{~h}$ were lethal to mice. This lethality increased during the exponential phase and remained steady at maximal level throughout the stationary phase. There was good reproducibility of growth in the control cultures performed on five separate occasions; the mean growth rate for the five cultures was $1.76 / \mathrm{h}$ (range $1 \cdot 55-1 \cdot 95 / \mathrm{h}$ ) and the mean yield at $10 \mathrm{~h}$ of growth equal to $4.02 \mathrm{mg} / \mathrm{ml}$ (range 3.84 $\mathrm{mg} / \mathrm{ml}, E 600$ of $13 \cdot 0$, to $4 \cdot 11 \mathrm{mg} / \mathrm{ml}, E 600$ of $15 \cdot 2$ ). The maximum levels of exocellular enzymes and lethality were similar in all five repeat tests, although individual values were not directly comparable due to differences in their sampling times. The levels for exocellular products were in the following ranges: LD50 8-16 units $/ \mathrm{ml}$; acid phosphatase, $(27-32) \times 10^{-3}$ units $/ \mathrm{ml}$; lipase $14 \cdot 7-8 \cdot 1$ units $/ \mathrm{ml}$; proteinase $18-20$ units/ml; hyaluronate lyase (2.6-9.4) $\times 10^{-3}$ units $/ \mathrm{ml}$; haemolysin $1024-4096$ units $/ \mathrm{ml}$. 

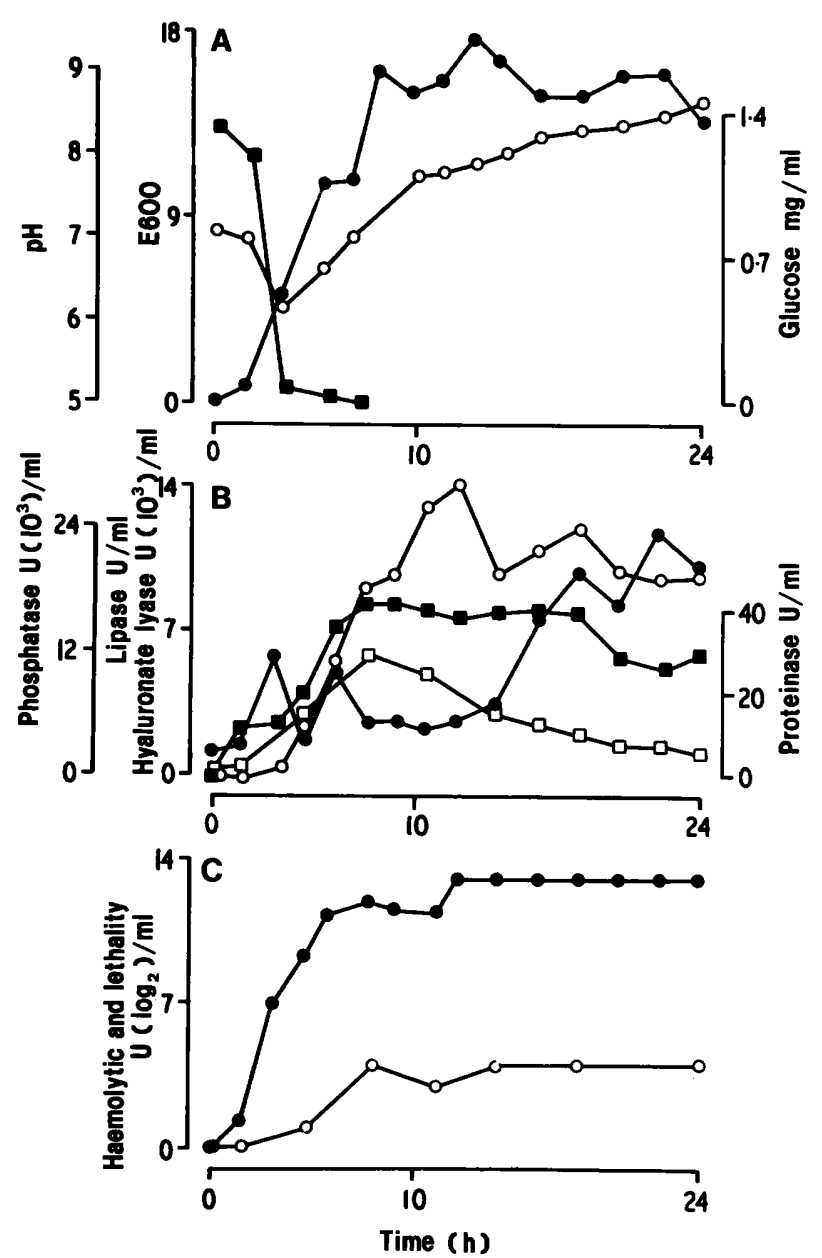

FIG. 1.-Growth and exocellular product formation by S. aureus FRI 1187 in BHI plus salts. (A) $-\longrightarrow E$ $600 \mathrm{~nm} ; 0 \longrightarrow \mathrm{OH} ; \square$ glucose. (B) $\longrightarrow$ acid phosphatase; $\bigcirc-0$ lipase; hyaluronate lyase; $\square \longrightarrow$ proteinase. (C) $\longrightarrow$ haemolysin; $O \longrightarrow 0$ lethality for mice.

\section{Effects of tampon materials on the growth of S. aureus FRI 1187}

The initial growth rates (growth rate during first $3 \mathrm{~h}$ ) and cell yield at $10 \mathrm{~h}$ for the seven cultures of FRI 1187 containing the different test materials and the control culture grown simultaneously are given in table $\mathrm{I}$. The curves for growth in the presence of R4, MAR, C and CMC are shown in fig. 1. The initial rate of growth in the presence of each of the materials tested was below the lower limit of initial growth determined in the five control cultures. $\mathrm{C}$ and MAR apparently induced a very long lag phase (fig. $2 \mathrm{C}$ and $\mathrm{D}$ ). However, the $p \mathrm{H}$ profile and rate of glucose utilisation in the culture containing $\mathrm{C}$ were similar to those of the control culture. Phase contrast microscopy of the samples from the culture containing $\mathrm{C}$ revealed that, during the first $9 \mathrm{~h}$ of growth, the cells adhered to the material. This did not occur in the cultures containing the other six materials. This indicated that in the culture containing $\mathrm{C}$, the optical density 
measurement did not reflect the amount of growth in this culture. In the presence of MAR, glucose utilisation did not commence for $8 \mathrm{~h}$ and the $p \mathrm{H}$ did not alter for $11 \mathrm{~h}$. This suggested that there was an extended lag phase in this culture.

Two samples of unmodified rayon (R2 and R3) increased or failed to affect the cell yield, but the remaining materials reduced it by different amounts (table I). Although the $p \mathrm{H}$ profiles of the various test cultures were different during the growth cycles, only $\mathrm{CMC}$ reduced the $p \mathrm{H}$ immediately upon its addition to the growth medium at time zero.

\section{Effects of tampon materials on the levels of exocellular products of S. aureus FRI 1187}

The effects of the materials on the exocellular product levels were different for different tampon materials (table I). All the materials tested reduced the maximum levels recorded for acid phosphatase, lipase, proteinase and haemolysin, with the exception of R2 in the presence of which the level of acid phosphatase increased 1.5-fold. Hyaluronate lyase levels were reduced in the presence of $\mathrm{C}$ and CMC but raised in the presence of $\mathrm{R} 2$ and MAR, other materials having little effect.

As it was possible that differences in exocellular enzyme levels merely reflected alterations in cell yield, the specific activities (units $\mathrm{ml}^{-1} / \mathrm{mg} \cdot \mathrm{cells}^{-1} \mathrm{ml}^{-1}$ ) at $10 \mathrm{~h}$ were calculated to take into account such changes in cell concentration. This calculation was not feasible for the cultures containing MAR and $\mathrm{C}$, because of the long lag or adherence of cells on to fibres noted in these cultures. The 10-h sample was chosen because maximum cell yield and high levels of products occurred in most of the cultures at this time. Comparison between cultures at different times of growth would be meaningless. Only CMC produced a decrease in the specific activities at $10 \mathrm{~h}$ for all of the enzymes measured (table I). The specific activity of haemolysin at $10 \mathrm{~h}$ was reduced in the presence of all of the test materials. The different rayon materials had different effects on the specific activities at $10 \mathrm{~h}$ of acid phosphatase and proteinase, whereas there was a tendency for the specific activity of lipase to be decreased by all the rayon materials and of hyaluronate lyase to be increased (table I). Further studies would be necessary to determine the significance of these differences.

Lethality of each culture filtrate was tested at $10 \mathrm{~h}$. The LD50 of the control culture was 12.44 units, but all seven test materials reduced the lethality to lower levels (table I).

\section{The effect of materials on preformed exocellular products of S. aureus FRI 1187}

Reduction of exocellular product levels in the cultures containing tampon materials could have been due to inactivation or adsorption of these proteins by the materials. An increase could have been due to adsorption of inhibitors or the release of co-factors by the materials. To determine whether these phenomena occurred, CMC (which caused the greatest reduction) and R4 (which had little effect) were tested for their ability to alter the levels of the products in a stationary-phase culture filtrate obtained after growth of $S$. aureus FRI 1187 in the control medium. The results are summarised in table II. Four 5-ml fractions of the untreated filtrate, the first PBS wash and the $\mathrm{NaCl}$-in-PBS wash, were collected and assayed. However, there was no fractionation of the activities within the fractions. The fractions for each step were 


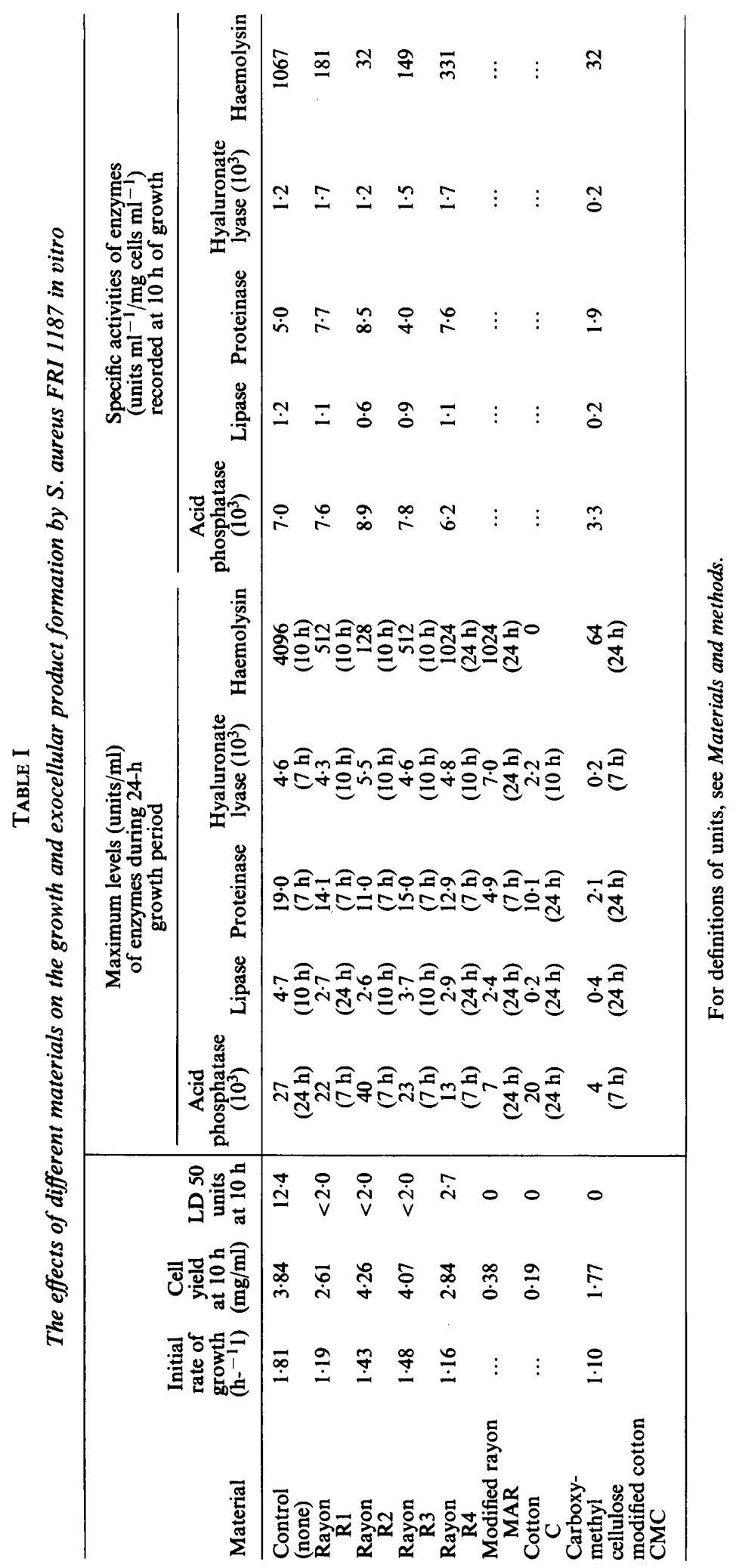



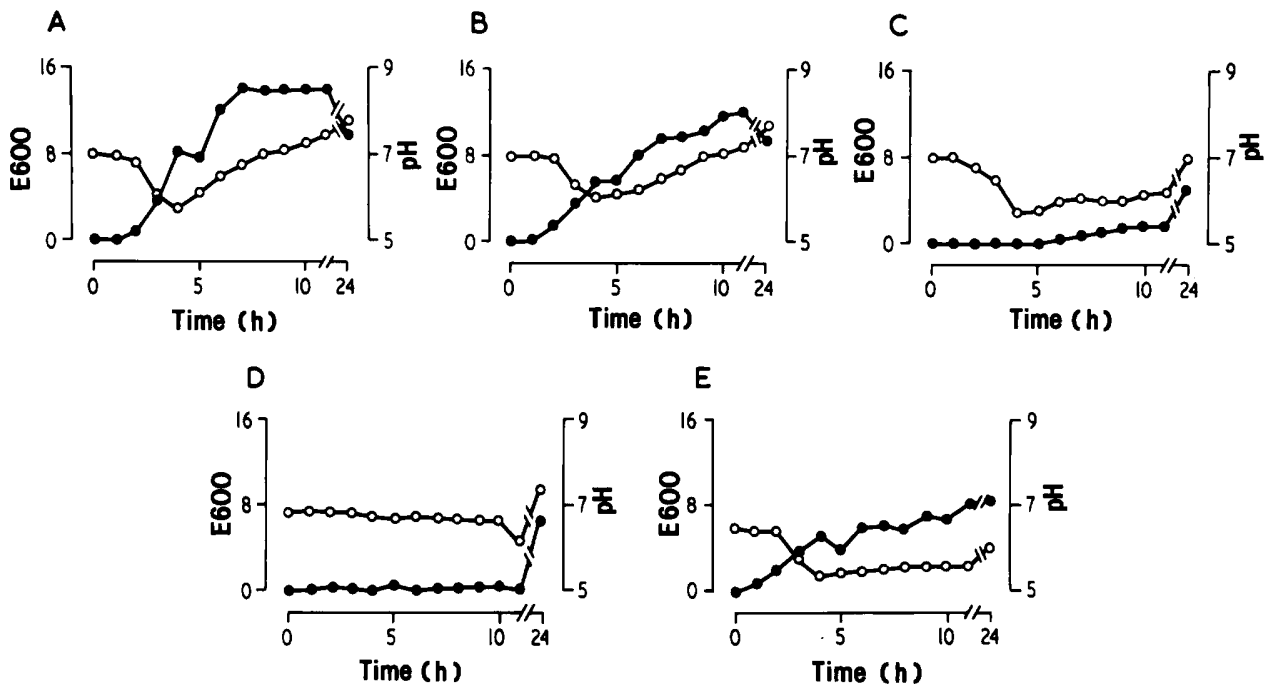

FIG. 2.-Comparison of the effects of different materials on the growth of $S$. aureus FRI 1187 in vitro: $-\quad E 600 \mathrm{~nm} ; \mathrm{O} \longrightarrow \mathrm{O} \mathrm{H}$; in the presence of $(\mathrm{A})$ no materials; (B) rayon (R4); (C) cotton (C); (D) modified rayon (MAR); (E) modified cotton (CMC).

\section{TABLE II}

The adsorption and recovery of $S$. aureus FRI 1187 exocellular products from culture filtrates treated with carboxy-methyl cellulose (CMC) and rayon fibres (R4)

\begin{tabular}{|c|c|c|c|c|c|c|c|c|c|}
\hline \multirow[b]{3}{*}{$\begin{array}{l}\text { Exocellular } \\
\text { product }\end{array}$} & \multirow{3}{*}{$\begin{array}{c}\text { Total } \\
\text { activity in } \\
\text { original } \\
\text { (untreated) } \\
\text { culture } \\
\text { filtrate }(20 \mathrm{ml} \text { ) }\end{array}$} & \multicolumn{8}{|c|}{ Percentage activity $\dagger$ recovered after incubation of filtrate with } \\
\hline & & \multicolumn{4}{|c|}{ CMC } & \multicolumn{4}{|c|}{ R4 } \\
\hline & & $\begin{array}{l}\text { treated } \\
\text { filtrate } \\
(20 \mathrm{ml})\end{array}$ & $\begin{array}{c}\text { first } \\
\text { wash with } \\
\text { PBS }(20 \mathrm{ml})\end{array}$ & $\begin{array}{l}\mathrm{NaCl} \text {-in- } \\
\text { PBS wash } \\
(20 \mathrm{ml})\end{array}$ & $\begin{array}{c}\text { Total } \\
\text { in } 60 \mathrm{ml}\end{array}$ & $\begin{array}{l}\text { treated } \\
\text { filtrate } \\
(20 \mathrm{ml})\end{array}$ & $\begin{array}{c}\text { first } \\
\text { wash with } \\
\text { PBS }(20 \mathrm{ml})\end{array}$ & $\begin{array}{l}\mathrm{NaCl} \text {-in- } \\
\text { PBS wash } \\
(20 \mathrm{ml})\end{array}$ & $\begin{array}{c}\text { Total } \\
\text { in } 60 \mathrm{ml}\end{array}$ \\
\hline Haemolysin & $10 \times 10^{2}$ & 100 & 50 & 0 & 150 & 140 & 12 & 0 & 152 \\
\hline Lipase & $1.4 \times 10^{2}$ & 87 & 28 & 5 & 120 & 66 & 8 & 1 & 75 \\
\hline Hyaluronate lyase & $5.0 \times 10^{-2}$ & 87 & 56 & 0 & 83 & 14 & 4 & 0 & 18 \\
\hline Acid phosphatase & $4.0 \times 10^{-2}$ & 13 & 11 & 27 & 51 & 33 & 16 & 10 & 59 \\
\hline Proteinase & $1.6 \times 10^{2}$ & 56 & 23 & 0 & 79 & 35 & 0 & 23 & 58 \\
\hline
\end{tabular}

$\mathrm{CMC}=$ carboxy-methyl cellulose cotton linters; $\mathrm{R} 4=$ unmodified rayon + Units $/ \mathrm{ml} \times$ volume.

therefore combined and the results presented as total activities recovered at each stage. CMC loosely bound some of all of the enzymes, as indicated by the recovery of activities in the first PBS wash. However, CMC adsorbed appreciable amounts $(27 \%)$ only of the acid phosphatase, which was recovered only after washing with $\mathrm{NaCl}$. Treatment of the culture filtrate with CMC resulted in a $50 \%$ increase in haemolysin activity and a $20 \%$ increase in lipase activity. This was not due to absorption of fluid by the material, as virtually all of the fluid was recovered by use of positive pressure. Treatment of the culture filtrate with $\mathrm{R} 4$ resulted in reduced enzyme, but increased $(52 \%)$ haemolysin activities. The R4 treatment resulted in a $40 \%$ decrease in the levels of proteinase and acid phosphatase. Hyaluronate lyase activity recovery was even lower $(18 \%)$. R4 loosely bound only a small proportion of the activities, or nil in the 
case of proteinase, where adsorption ( $23 \%$ ) was highest. Lethality was also tested, but was unaffected by treatment with either CMC or R4.

Metal ion analysis was performed on the culture filtrate before and after adsorption with CMC and $\mathrm{R} 4$. There was a slight increase in both $\mathrm{Fe}^{2+}$ and $\mathrm{Ca}^{2+}$ after treatment with the materials. Before treatment, the filtrates contained $\mathrm{Fe}^{2+} 18.6 \mu \mathrm{mol} / \mathrm{L}$ and $\mathrm{Ca}^{2+} 0 \cdot 14 \mu \mathrm{mol} / \mathrm{L}$. After treatment, the $\mathrm{Fe}^{2+}$ content was 26.4 and $22.5 \mu \mathrm{mol} / \mathrm{L}$ for CMC-treated and R4-treated filtrates, respectively, and the $\mathrm{Ca}^{2+}$ content was 0.22 $\mu \mathrm{mol} / \mathrm{L}$ for both the CMC-treated and R4-treated culture filtrates. The $\mathrm{Na}^{+}, \mathrm{K}^{+}, \mathrm{Cl}^{-}$ and $\mathrm{PO}_{4}{ }^{2-}$ levels were unaffected by the treatment.

\section{Discussion}

This study was primarily concerned with growth, haemolysin and exocellular enzyme production by one TSS-producing strain of $S$. aureus (FRI 1187). The results illustrate that there is probably a highly complex interaction between the metabolism of the organism and materials used in tampon construction.

Two types of material were used in this study, five that were unmodified, rayon (R1-R4) and cotton (C), and two that had increased absorption properties as a result of chemical modification of rayon (MAR) and cotton (CMC). Most of the materials tested showed some reduction in growth rate, cell yield and exocellular product levels as compared with control values. The most pronounced effects, however, were observed with the chemically modified materials. CMC was the only material tested which decreased the specific activities of all of the exocellular products, suggesting an overall suppression of exocellular product formation when $S$. aureus FRI 1187 was grown in the presence of this material. The effects of the normal materials were different for the different materials. Unmodified cotton (C) had the most pronounced effect in reducing cell yield, growth rate and exocellular product formation. The reasons for the different effects are unknown but could not be explained by large changes in the concentration of the metal ions which were assayed. However, these measurements were performed against a background of many unknown organic molecular species in BHI.

Adsorption experiments with CMC and R4 were performed in an attempt to determine whether the alterations in exocellular product levels produced by $S$. aureus in the presence of the materials could be explained by adsorption, inactivation or stimulation by the materials acting directly upon the already-formed proteins. It was surprising to observe that CMC enhanced haemolysin activity (by $50 \%$ ) after treatment of control filtrates with this material, whereas the level of haemolysin had been reduced (by $97 \%$ ) by CMC in the growth experiment. This may indicate that CMC affects not only the production of haemolysin by $S$. aureus FRI 1187 but also the already-formed protein. The changes in enzyme and haemolysin levels recorded in the adsorption experiment could be due to activation or the removal of inhibitory substances (e.g., the increase in haemolysin activity after adsorption with CMC) or, alternatively, inhibition or the removal of co-factors (as observed for the loss of hyaluronate lyase after adsorption with CMC and R4) or simple adsorption (as observed for the effect of CMC and R4 on acid phosphatase and R4 on proteinase).

Interpretation of these results is extremely difficult, as there appear to be different effects for different fibres on different exocellular products. Moreover, as the results are 
based on single experiments, with one strain of $S$. aureus, the study can only be regarded as preliminary. However, the results strongly suggest that materials used in tampon manufacture may affect exocellular product formation, directly or indirectly, by at least one strain of $S$. aureus. Furthermore, different batches of the same material may have different effects.

Clearly, there is a need for extensive further studies to elucidate the nature of the interactions between more strains of $S$. aureus and tampon materials. In view of the finding that materials used in tampons may affect the levels of some exocellular products of $S$. aureus, it would be of considerable importance to determine whether these materials also affect the levels of Toxic Shock Syndrome toxin I produced by this and other TSS strains of $S$. aureus. However, such investigations await the development of a simple, specific, reproducible and quantitative in-vitro assay for this toxin.

\section{REFERENCES}

Barbour A G 1981 Vaginal isolates of Staphylococcus aureus associated with Toxic Shock Syndrome. Infection and Immunity 33:442-449.

Bergdoll M S, Crass B A, Reiser R F, Robbins R N, Davis J P 1981 A new staphylococcal enterotoxin, enterotoxin F, associated with Toxic Shock-Syndrome Staphylococcus aureus isolates. Lancet 1:1017-1021.

Broome C V et al 1982 In-vitro studies of interactions between tampons and Staphylococcus aureus. Annals of Internal Medicine 96:959-962.

Eady E A, Ingham E, Holland K T, Gowland G 1983 Interactions of tampon fibres with growth of Staphylococcus aureus in vitro. Lancet 1:818.

Ingham E, Holland K T, Gowland G, Cunliffe W J 1979 Purification and partial characterization of hyaluronate lyase (EC 4.2.2.1) from Propionibacterium acnes. Journal of General Microbiology 115:411-418.

Ingham E, Holland K T, Gowland G, Cunliffe WJ 1980 Purification and partial characterization of an acid phosphatase (EC 3.1.3.2) produced by Propionibacterium acnes. Journal of General Microbiology 118:59-65.

Ingham E, Holland K T, Gowland G, Cunliffe W J 1981 Partial purification and characterization of lipase (EC 3.1.1.3) from Propionibacterium acnes. Journal of General Microbiology 124:393-401.

Ingham E, Holland K T, Gowland G, Cunliffe W J 1983 Studies of the extracellular proteolytic activity produced by Propionibacterium acnes. Journal of Applied Bacteriology 54:263-271.

Millet J 1970 Characterization of proteinases excreted by Bacillus subtilis Marburg strain during sporulation. Journal of Applied Bacteriology 33:207-219.

Reed L J, Muench H 1938 A simple method of estimating fifty percent end points. American Journal of Hygiene 27:493-497.

Schlievert P M 1983 Alteration of immune function by staphylococcal pyrogenic exotoxin Type C: Possible role in Toxic Shock Syndrome. Journal of Infectious Diseases 147:391-398.

Schlievert P M, Osterholm M T, Kelly J A, Nishimura R D 1982 Toxin and enzyme characterization of Staphylococcus aureus isolates from patients with and without Toxic Shock Syndrome. Annals of Internal Medicine 96:937-940.

Schlievert P M, Shands K N, Dan B B, Schmid G P, Nishimura R D 1981 Identification and characterization of an exotoxin from Staphylococcus aureus associated with Toxic-Shock Syndrome. Journal of Infectious Diseases 143:509-516.

Vergeront J M, Evenson M L, Crass B A, Davis J P, Bergdoll M S, Wand P J, Noble J H, Petersen G K 1982 Recovery of staphylococcal enterotoxin F from the breast milk of a woman with Toxic-Shock Syndrome. Journal of Infectious Diseases 146:456-459. 